\title{
Dermatología y entomología
}

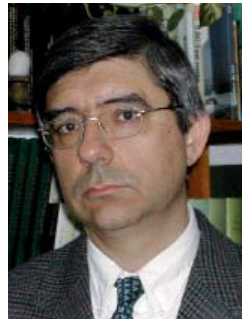

José Luis Viejo Montesinos

Catedrático de Zoología. Departamento de Biología. Universidad Autónoma de Madrid.
Se cuenta que, cuando presentaron a don José Ortega y Gasset al torero Rafael El Gallo mediante la habitual fórmula «aquí, Rafael El Gallo, torero; aquí don José Ortega y Gasset, filósofo", el torero respondió por lo bajo: «Hay gente pa to». Pues eso nos pasa a veces a los entomólogos. Realmente hay gente $p a$ to, hasta para estudiar los insectos, los arácnidos y otros artrópodos.

Los artrópodos son tan numerosos, ubicuos y diversos que se cuentan por decenas las actividades humanas en las que de algún modo intervienen. Agricultura, ganadería, pesca, industrias de toda índole, literatura, arte, criminología, medicina... son algunos de los campos donde la entomología puede ayudar a afrontar algunos problemas y hasta incluso a resolverlos. Sin embargo, a pesar de esta presencia de los insectos y otros artrópodos en las actividades humanas más dispares, me temo que el papel del entomólogo sigue siendo marginal y anecdótico, cuando no ignorado. Y ésta es la razón principal que me mueve a divulgar en este foro la labor de estos zoólogos, con frecuencia representados con salacot, pantalones cortos y una manga entomológica (vulgo cazamariposas) en la mano, y que también pueden contribuir a la dermatología con alguna modesta aportación.

Según la clasificación propuesta por alguno de nuestros maestros ${ }^{1}$, los artrópodos afectan a la salud humana:
- Por acción indirecta: vectores de patógenos (pasivos u obligados) y portadores foréticos de artrópodos perjudiciales.

- Por acción directa: molestias, daño accidental a órganos, envenenamiento, dermatosis, miasis y fobias.

En el ámbito de las enfermedades de la piel, podemos encontrar artrópodos tanto en uno como en otro tipo de acción, aunque son más frecuentes en el segundo. Entre las manifestaciones cutáneas de enfermedades transmitidas por insectos, podemos mencionar algunas leishmaniosis, como el botón de Oriente, causado por el protozoo zooflagelado Leishmania tropica (entre otras especies del mismo género), que es transmitido por el mosquito Phlebotomus sergenti (y otros flebótomos) y que tiene reservorios en perros y en humanos; esta leishmaniosis se manifiesta al principio como una pápula eritematosa, que crece y se rodea de pequeñas pápulas satélites, con frecuencia en la cara. Esta enfermedad, aunque conocida desde hace un siglo en nuestro país, es rara en España. La filariosis linfática está causada por nematodos parásitos de los géneros Wuchereria y Bruggia, transmitidos por mosquitos del género Culex. La loiasis es una filariosis africana causada por el nematodo Loa loa, que se instala en el tejido subcutáneo e incluso en la conjuntiva ocular; las microfilarias infectantes son inoculadas por moscas del géne- 
ro Chrysops. La oncocercosis, o ceguera de los ríos, es causada por la filaria Onchocerca volvulus, un nematodo de hasta $50 \mathrm{~cm}$ de longitud y apenas $1 \mathrm{~mm}$ de grosor que puede producir ceguera por queratitis y lesiones en la retina; las microfilarias infectivas son transmitidas por unos diminutos mosquitos (Simulium); se estima que la oncocercosis afecta a 18 millones de personas en África Central y América Central y Meridional. También es un nematodo Dracunculus medinensis o filaria de Medina, agente causal de la dracontiasis, que tiene un crustáceo copépodo (Cyclops) como huésped intermedio y que se ingiere con aguas infectadas; la hembra del helminto alcanza hasta $1 \mathrm{~m}$ de longitud y apenas $1 \mathrm{~mm}$ de grosor, y se instala en el tejido subcutáneo; las imágenes de la cuidadosa extracción del gusano a través de la úlcera que produce, mediante su enrollamiento en una cerilla, son una de las pesadillas que recurrentemente nos asaltan a muchos biólogos; para consolarnos, repasamos su distribución geográfica: áreas secas de África, la India y Yemen.

Por acción directa, los artrópodos causan bastantes problemas de salud; ciñéndonos en esta secuencia enumerativa a las dolencias relacionadas con la piel, tenemos necesariamente que mencionar cinco grandes categorías: acción directa sin mediar veneno, envenenamiento (básicamente por picaduras), contacto, inhalación y fobias. En la primera categoría, se incluyen las pediculosis, miasis, sarna y afecciones causadas por demodícidos y garrapatas, entre muchos otros ácaros. De todas estas infestaciones, sólo la pediculosis tiene una amplia incidencia en España, más por cuestiones psicosociales que puramente médicas; para una amplia información acerca de los piojos humanos y su control, remitimos al lector a la excelente revisión de Burgess (2004)²; como curiosidad, y en relación con los piojos humanos, cabe mencionar una publicación ${ }^{3}$ reciente en la que se establece la antigüedad del uso de la ropa por la edad estimada de la separación evolutiva entre el piojo del cuero cabelludo (Pediculus humanus capitis o Pediculus capitis, según opiniones), el antepasa- do, y el piojo del cuerpo o de la ropa (Pediculus humanus), que se estima en 83.000 años, como poco, y 170.000 como mucho; si tenemos en cuenta que la estirpe humana perdió su pelambrera corporal hace poco más de 1 millón de años, resulta que la mayor parte de la historia evolutiva de nuestra estirpe la hemos pasado en pelota. Las miasis consisten en el desarrollo de larvas de mosca en la piel y los tejidos subcutáneos que, literalmente, te comen vivo; aunque los huéspedes suelen ser el ganado vacuno, ovino e incluso los venados (dípteros Oestridae, Cuterebridae, etc.), eventualmente afectan a los seres humanos; en el caso de los dípteros Gasterophilidae, las larvas pueden ser tragadas y causar irritación en la mucosa gástrica. Existen decenas de especies de dípteros causantes de uno u otro tipo de miasis en los seres humanos, aunque no tenemos noticias de casos en España. Afín a este planteamiento biológico, aunque de efectos médicos diferentes, es el uso de larvas de mosca para la limpieza de heridas gangrenadas ${ }^{4}$, un viejo remedio de la medicina popular ahora reivindicado. Las niguas son unas pulgas tropicales (Tunga penetrans) que causan graves úlceras en los pies de personas que caminan descalzas por las zonas arenosas donde son frecuentes; esta especie, originaria de la América tropical, se ha extendido por África y el sur de Asia. Se conocen casos en España.

Los ácaros son un grupo de arácnidos de enorme diversidad taxonómica y ecológica, del que se conocen unas 40.000 especies en el mundo, pero el número de las realmente existentes debe ser mucho mayor ${ }^{5}$; de interés dermatológico, hay varias decenas de especies, entre las que obligadamente tenemos que mencionar Sarcoptes scabiei, el arador de la sarna, que puede afectar indistintamente a los seres humanos y a otros mamíferos, si bien la infestación humana por ácaros procedentes de perros, caballos u otros animales domésticos cura espontáneamente, no así la transmitida de persona a persona. De menor importancia son las infestaciones con demodícidos, ya que en la mayor parte de los casos son asintomáticas; estos diminutos 
ácaros (pocas décimas de milímetro) viven en el folículo piloso. Se estima que más de la mitad de las personas adultas pueden ser portadoras de Demodex (principalmente $D$. foliculorum) y prácticamente nunca lo advertirán. Los trombicúlidos causan dermatitis por picadura; se trata de ácaros rojizos de alrededor de $1 \mathrm{~mm}$, a menudo asociados a la vegetación o a los pajares (por ejemplo, la sarna de los pajares causada por Piemotes).

Mención aparte merecen los artrópodos venenosos que causan problemas dérmicos, como las arañas; en este orden están las Loxosceles (Sicariidae) o las Tegenaria (Agelenidae), arañas con veneno necrosante e histolítico, cuya picadura es de difícil tratamiento. Por picadura también crean problemas dérmicos los himenópteros provistos de aguijón, como las avispas (Vespidae), las abejas y abejorros (Apidae) y las hormigas. Las primeras poseen un aguijón que penetra y sale de la piel afectada; con él pueden inocular un veneno que contiene serotonina y acetilcolina; los ápidos suelen tener un aguijón con barbas que entra con facilidad en la piel, pero que una vez clavado no puede salir; el veneno posee mellitina, histamina, apamina y polipéptido MCD. Problemas por picaduras también pueden causar unos pequeños himenópteros (menos de $3 \mathrm{~mm}$ ) de la familia Bethylidae, normalmente parasitoides de carcomas (coleópteros Anobiidae), pero que eventualmente pueden afectar a las personas cuando se remueven trastos viejos, desvanes y otros lugares propicios para la carcoma. Cercanos a las avispas son los mutílidos, cuya apariencia recuerda a hormigas con pelo, que infieren fuertes picotazos. Las hormigas también pueden tener aguijón y picar, aunque en España son poco frecuentes, si bien algunas especies producen irritaciones en la piel al expulsar nubes de ácido fórmico (Formica). En muchos casos, los problemas no vienen tanto por la picadura en sí como por las reacciones alérgicas subsiguientes.

Aunque no estrictamente venenosos, la picadura de insectos hematófagos puede acarrear también problemas dérmicos, como es el caso de Culicidae (mosquitos), Ceratopogonidae (jejenes, como los pequeños Culicoides), Simulidae, Tabanidae (tábanos), etc. Otros insectos son perjudiciales por contacto, como es el caso de las orugas de muchos lepidópteros; un paradigma de este tipo de afección es la causada por la procesionaria del pino (Thaumetopoea pityocampa), cuyos pelos urticantes producen dermatitis de contacto y conjuntivitis, incluso sin necesidad de tocar las orugas, ya que los pelos pueden ser transportados por el viento y afectar a los paseantes en los pinares con bolsones de esta plaga forestal.

Para completar este fresco, no podemos dejar de mencionar las fobias con efectos dermatológicos, como el síndrome de Ekbom o delirio de dermatozoos, por el que las personas afectadas están persuadidas de que son literalmente comidas por los «bichos». Este trastorno psiquiátrico es frecuentemente detectado en primera instancia por dermatólogos o incluso por entomólogos ${ }^{6}$.

\section{BIBLIOGRAFÍA}

1. Fernández Rubio F. Artrópodos y salud humana. Anales del Sistema Sanitario de Navarra, Monografía no 1. Pamplona: Gobierno de Navarra; 1999.

2. Burgess IF. Human lice and their control. Annu Rev Entomol. 2004;49:457-81.

3. Toups MA, Kitchen A, Light JE, Reed DL. Origin of clothing lice indicates early clothing use by anatomically modern humans in Africa. Mol Biol Evol. 2011;28(1):29-32.

4. Sherman RA, Hall M J, Thomas S. Medicinal maggots: an ancient remedy for some contemporary afflictions. Annu Rev Entomol. 2000;45:55-81.

5. Ortuño VM, Martínez-Pérez FD. Diversidad de artrópodos en España. Memorias R Soc Esp Hist Nat, 2ª ép. 2011;9. En prensa.

6. Viejo JL, Sánchez C. Una infestación parasitaria por insectos ficticia. Descripción de un caso de Síndrome de Ekbom. Bol R Soc Esp Hist Nat (Biol). 2010;104:47-9. 